Copyright (C) 2018 Elsevier Ltd. All rights reserved. This is the accepted manuscript version of an article which has been published in final form at https://doi.org/10.1016/j.matchar.2018.01.017, archived on this repository under a Creative Commons CC BY-NC-ND attribution licence.

Materials Characterization Volume 137, March 2018, Pages 39-49

\title{
Effect of Bi on the microstructure and mechanical properties of $\mathrm{Sn}-\mathrm{Zn}$ alloys processed by rolling
}

Guangyu Liu, Shouxun Ji

Brunel Centre for Advanced Solidification Technology (BCAST), Institute of Materials and Manufacturing, Brunel University, Uxbridge, Middlesex UB8 3PH, London, United Kingdom https://doi.org/10.1016/j.matchar.2018.01.017Get rights and content

Highlights

- $\mathrm{Sn}-\mathrm{Zn}-\mathrm{Bi}$ is proposed for the first time as the cladding in linear explosive device.

- Bi can significantly refine the microstructure of Sn-Zn.

- Bi can enhance both strength and ductility of Sn-Zn processed by rolling.

- The $5 \mathrm{wt} \% \mathrm{Bi}$ in $\mathrm{Sn}-3 \mathrm{Zn}$ leads to finest and most homogenous grains after rolling.

\begin{abstract}
Sn-Zn based alloys including Sn-3Zn, Sn-3Zn-1Bi, and Sn-3Zn-5Bi were prepared by casting and rolling, in efforts to assess their feasibility for the application as cladding materials in detonating and explosive cords. It was found that Bi significantly refined the solidification microstructure, changing the configuration of Sn-Zn eutectic from well-aligned Zn-rich precipitates/needles to misaligned Zn-rich flakes. During deformation, second phases like Znrich precipitates and $\mathrm{Bi}$ particles, and $\mathrm{Bi}$ solutes were effective in grain refinement since second phase particles provided more sites for nucleation and more obstacles to growth of new recrystallized grains. Tensile results revealed that $\mathrm{Bi}$ addition enhanced both strength and ductility of the rolled Sn-Zn-Bi alloys. The Sn-3Zn-5Bi alloy possessed superior strength and ductility (UTS: $84.4 \mathrm{MPa}$; Yield strength: $68.3 \mathrm{MPa}$; Elongation: 75.2\%) due to its finest and most homogeneous equiaxed grains. Based on decent mechanical properties, the Sn-Zn-Bi alloys could be well qualified for the application as cladding materials.
\end{abstract}

\section{Keywords}

Sn-Zn-bi alloysCladding materialsDeformationRecrystallizationMicrostructureMechanical properties

\section{Introduction}

Linear explosive devices, such as detonating and explosive cords, can be used for severing, cutting, fracturing, or impacting a target material or structure. One example of how such devices may be used is the clearance of aircraft canopies. A detonating and explosive cord near the inside of the canopy propels the sheath/cladding outward at a high velocity, thereby penetrating 
or shattering the canopy to clear an escape path [1,2]. Detonating and explosive cords are typically flexible cylindrical cords with an explosive core and a robust cladding material to contain the explosive and to provide mechanical strength [3]. The metallic cladding is the key part of the linear explosive device because it can effectively enhance the cutting performance by means of the shaped charge effect $[4,5]$.

For decades, the cladding materials were often made by lead $(\mathrm{Pb})$ and/or Pb-based alloys [6]. However, due to the environmental and human health concerns regarding lead poisoning and the increasingly strict requirement in environmental legislations, the substitute of currently used $\mathrm{Pb}$-based alloys has been attractive for recent development of new generation metallic cladding materials in aerospace industry [7]. The requirements of cladding materials for detonating and explosive cords have been summarized as following [8]: (1) Non-toxicity to meet the requirement in health and environment; (2) Abundant resource of elements for making alloys to meet current and future needs; (3) Low cost of the element for industrial application; (4) High density, ideally close to lead-based alloys, to impart sufficient impulse, impact energy, and momentum during the flight of fractured and fragmented piece of cladding materials for penetrating; (5) Acceptable mechanical properties for manufacturing, in particular of the capability of deformation together with high energy materials. (6) Reasonably good performance in melting, casting, and deforming.

The application of lead-free tin ( $\mathrm{Sn}$ )-based alloys to replace Pb-based alloys have been the topics of numerous studies as soldering and electronic assemblies for years [9]. For example, $\mathrm{Sn}-\mathrm{Ag}$ [10], $\mathrm{Sn}-\mathrm{Cu}$ [11], and $\mathrm{Sn}-\mathrm{Ag}-\mathrm{Cu}$ systems [12] have been often used as solder materials. However, in addition to applications in soldering and electronic industry, Sn-based alloys have also been considered as cladding materials for linear explosive products due to its good workability, relatively high density, and small thermal neutrons absorption in high radiation environments [13]. Specifically, Rodney et al. [14] have reported that $\mathrm{Sn}-\mathrm{Sb}-\mathrm{Cu}$, and $\mathrm{Sn}-\mathrm{Bi}$ $\mathrm{Cu}-\mathrm{Ag}$ can be used as the outer sheath materials in ignition cords, mild detonating cords, and linear shaped charges. Graham et al. [13] have suggested Sn-(0.5-4) wt\%Ag to be the sheathing of mild detonating cords due to the good ductility, $\sim 88 \%$ in elongation. Recently, Huang et al. [15] have claimed the use of $\mathrm{Sn}-(0-20) \mathrm{wt} \% \mathrm{Cu} / \mathrm{Sb}$ as linear initiating explosive devices. These researches have certainly confirmed the capability of Sn-based alloys for the application as cladding materials in linear explosive device.

However, above mentioned $\mathrm{Cu}$ and/or $\mathrm{Ag}$ containing Sn-alloys unfortunately have some disadvantages. For instance, $\mathrm{Ag}$ is a high cost element which should be avoided in industrial manufacturing for large use. Plus, the big difference of the melting points between $\operatorname{Sn}\left(232{ }^{\circ} \mathrm{C}\right)$ and $\mathrm{Ag} / \mathrm{Cu}\left(961 / 1085^{\circ} \mathrm{C}\right)$ elements somehow hinders ease of casting. It is thus essential to develop new Sn-based alloys that are expected to be cost-effective and easy-to-manufacture, and certainly with no or least deterioration in mechanical performance. In comparison with other Sn-based alloys, Sn-Zn and Sn-Zn-Bi alloys have unique characteristics, which include low melting temperature $[16,17]$, low cost [18], and proper mechanical properties (UTS: 50 $90 \mathrm{MPa}$, elongation:10-25\%) [19, 20]. Bi was reported to improve the reliability of Sn-Zn alloys by optimization of mechanical properties based on the solid solution effects of Bi atoms and precipitation strengthening by Bi particles [21]. 
Therefore, the aim of the present work is to investigate the feasibility of developing a costeffective and easy-manufacturing Sn-Zn based alloys, which can be used as new cladding materials for detonating and explosive cords. For the first time, the microstructure and mechanical properties of Sn-3Zn, Sn-3Zn-1Bi, and Sn-3Zn-5Bi alloys were studied after mechanical deformation by rolling. Significantly, $\mathrm{Bi}$ is found to enhance both the strength and ductility of the rolled Sn-Zn-Bi alloys. The relationship between the microstructure and tensile properties of rolled specimens were discussed in association with the influence of Bi solutes and second phases on refinement of dynamic crystallized microstructure.

\section{Experimental}

\subsection{Sample Preparation}

$\mathrm{Sn}, \mathrm{Zn}$, and Bi ingots with commercial purity (99.9\%) were used as the raw materials. Prior to melting, each element was weighed to a specified ratio with specified burning loss compensation. The melt was prepared in a stainless steel crucible coated with A12O3 coatings and the melting was conducted in an electric resistance furnace. After melting, the melt with temperature around $360^{\circ} \mathrm{C}$ was manually poured into a metallic mold (preheated at $200{ }^{\circ} \mathrm{C}$ ) to form casting bars. All the casting bars were $300 \mathrm{~mm}$ long and had a trapezoid-shaped cross section of $20 \times 16 \times 16 \mathrm{~mm}$, as shown in Fig. 1 . The actual compositions of the experimental alloys were analyzed by the inductively coupled plasma atomic emission spectroscopy (ICPAES, ARCOS, Simultaneous ICP Spectrometer, SPECTRO Analytical Instruments GmbH, Germany), as shown in Table 1.

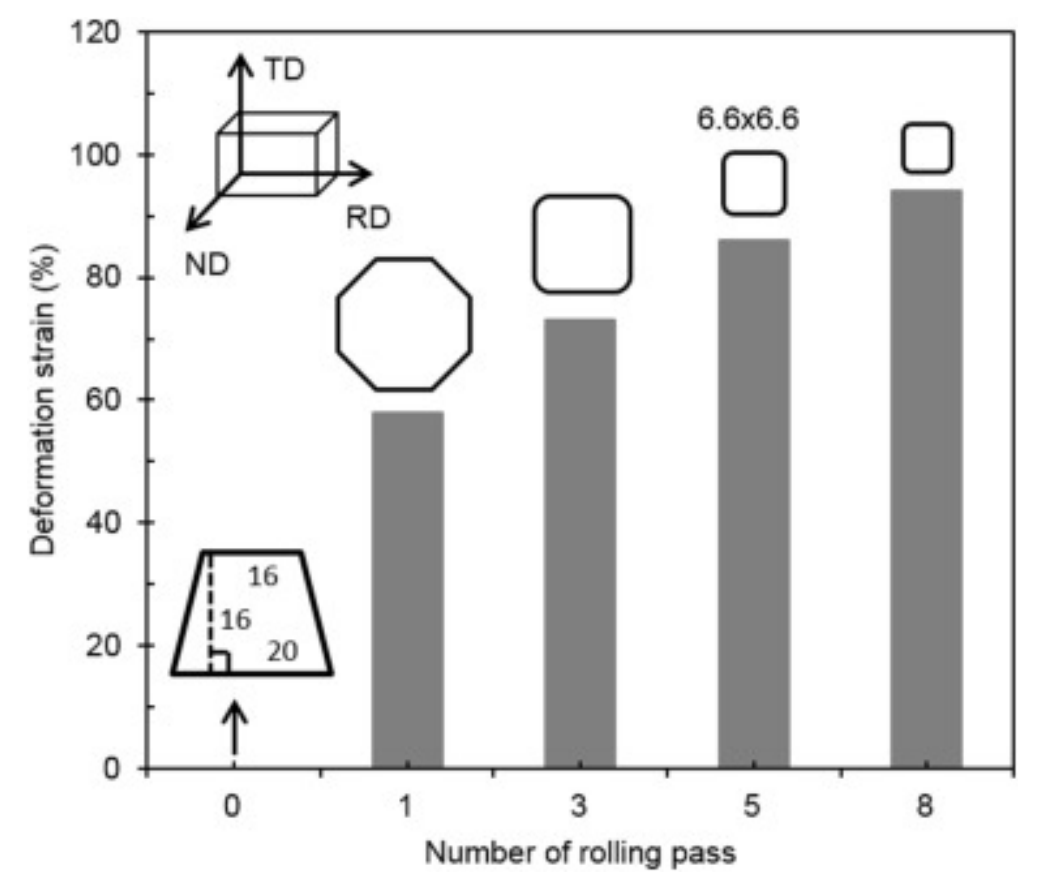

Fig. 1. Schematic diagram showing the variation of cross section and the deformation strain ratios with increasing the rolling pass (TD: transverse direction, ND: normal direction, RD: rolling direction). 
Table 1. Chemical composition of the experimental Sn-Zn-Bi alloys analyzed by inductively coupled plasma atomic emission spectroscopy (ICP-AES), wt\%.

$\begin{array}{llllllllll}\text { Alloys Zn } & \mathrm{Bi} & \mathrm{Ni} & \mathrm{Cu} & \mathrm{Fe} & \mathrm{Sb} & \mathrm{As} & \mathrm{Cd} & \mathrm{Sn} & \\ \text { Sn-3Zn } & 3.11 & 0.03 & 0.01 & 0.015 & 0.01 & 0.02 & 0.014 & 0.006 & \text { Rem. } \\ \text { Sn-3Zn-1Bi } & 2.89 & 0.98 & 0.01 & 0.012 & 0.01 & 0.02 & 0.008 & 0.006 & \text { Rem. } \\ \text { Sn-3Zn-5Bi } & 3.09 & 5.21 & 0.01 & 0.016 & 0.01 & 0.03 & 0.012 & 0.007 & \text { Rem. }\end{array}$

The casting bars were rolled at room temperature using a rolling machine (Durston FSM200 Rolling Mill, UK). The nominal diameter of roller is $110 \mathrm{~mm}$. There are 24 square grooves on the roller surface to form square bars. Rolling ratios of as-cast products to final products are presented in Fig. 1. The deformation strain was referred as the cross-section area reduction. The rolling machine was operated at a rolling speed of $5 \mathrm{rpm}$, which equaled to the rolling velocity of $3.1 \times 10-2 \mathrm{~m} / \mathrm{s}$. More details of alloy preparation and rolling process can be referred to previous work [8].

\subsection{Mechanical Testing}

The samples for tensile properties were machined from the rolled bars (after rolling 5 passes). The test part was $30 \mathrm{~mm}$ long and $6 \mathrm{~mm}$ in diameter. The tensile tests were conducted following the ASTM B557 standard using an Instron 5500 Universal Electromechanical Testing Systems equipped with Bluehill software and a $\pm 50 \mathrm{kN}$ load cell. All the tests were performed at ambient temperature $\left(20^{\circ} \mathrm{C}\right)$ with a strain rate of $2.0 \times 10-3 \mathrm{~s}-1$. Each data reported was based on the properties obtained from 5 to 7 samples.

\subsection{Microstructure Characterization}

X-ray diffraction (XRD) for phase identification of the as-cast alloys was carried out using Rigaku D/max 2550 diffractometer with $\mathrm{CuK} \alpha$ radiation. Plan-view and cross-sectional microstructural characterization was conducted before and after deformation using backscatter electrons (BSE) observation and electron backscattered diffraction (EBSD) technique in a Zeiss Supra 35VP field emission scanning electron microscopy (SEM) equipped with Energydispersive X-ray spectroscopy (EDX) working at $20 \mathrm{KV}$. The surface preparation for EBSD was conducted by SiC paper grinding and mechanical polishing by $0.05 \mu \mathrm{m}$ colloidal silica suspension. The EBSD scanning step size was $0.9 \mu \mathrm{m}$. The microstructure data were analyzed using TSL OIM 7.3 software to acquire detailed information on grain orientation, boundary characteristics and to identify grains with internal misorientation smaller than $2^{\circ}$. The clean-up method to orientation maps was performed using Grain CI Standardization (Grain Tolerance Angle: 3, and Minimum Grain Size: 2), giving very limited modification on original or actual results. 


\section{Results and Discussions}

\subsection{Effects of Bi on Solidification Microstructure}

Fig. 2 shows the backscattered SEM micrographs for the solidification microstructure of the Sn-3Zn, Sn-3Zn-1Bi, and Sn-3Zn-5Bi alloys. The matrix phase, white phase, and black phase were analyzed by EDS, corresponding phase information was illustrated in Fig. 3. It was clearly observed that the $\beta$-Sn phase was the primary phase. The microstructure of Sn-3Zn mainly consisted of the light gray primary $\beta$-Sn phase and Sn-Zn eutectics (Fig. 2a). The primary $\beta$-Sn phase exhibited dendrites morphology with the size being approximately $100-150 \mu \mathrm{m}$. The Sn$\mathrm{Zn}$ eutectic was in the form of alternate distribution of Sn phase and dark needle-like Zn-rich phase [22], possessing well-aligned acicular Zn-rich precipitates with relatively small spacing being 10-20 $\mu \mathrm{m}$ (Fig. 2b). When Bi was added, the microstructure was greatly changed in terms of the morphology, size, and distribution of both primary $\beta$-Sn phase and eutectics, in comparison with the microstructure of the $\mathrm{Sn}-3 \mathrm{Zn}$ alloy. The microstructure in the Sn-Zn-Bi alloys mainly comprised $\beta$-Sn phase, Zn-rich precipitates, and white Bi particles (Fig. 2c, d, e and f). Specifically, for Sn-3Zn-1Bi, clearly visible outlines of globular $\beta$-Sn dendrites were not easily observed any more. Normal eutectic cells made of alternately distributed $\mathrm{Sn}$ and $\mathrm{Zn}$ rich precipitates highlighted with dotted ellipses were rarely seen, whereas the misaligned Znrich precipitates in the form of relatively coarse flakes with sizes of approximately 3-5 $\mu \mathrm{m}$ were largely dispersed in the Sn matrix (shown by arrows in Fig. 2c and d). Aggregates of the white $\mathrm{Bi}$ particles tended to be randomly distributed in the vicinity of coarse $\mathrm{Zn}$-rich precipitates. When Bi content was increased to $5 \mathrm{wt} \%$, normal $\mathrm{Sn}-\mathrm{Zn}$ eutectic cells nearly disappeared and the Zn-rich precipitates became more homogenous (Fig. 2e). Much more regions of Bi aggregates formed, with individual Bi particle size being less than $1 \mu \mathrm{m}$. 

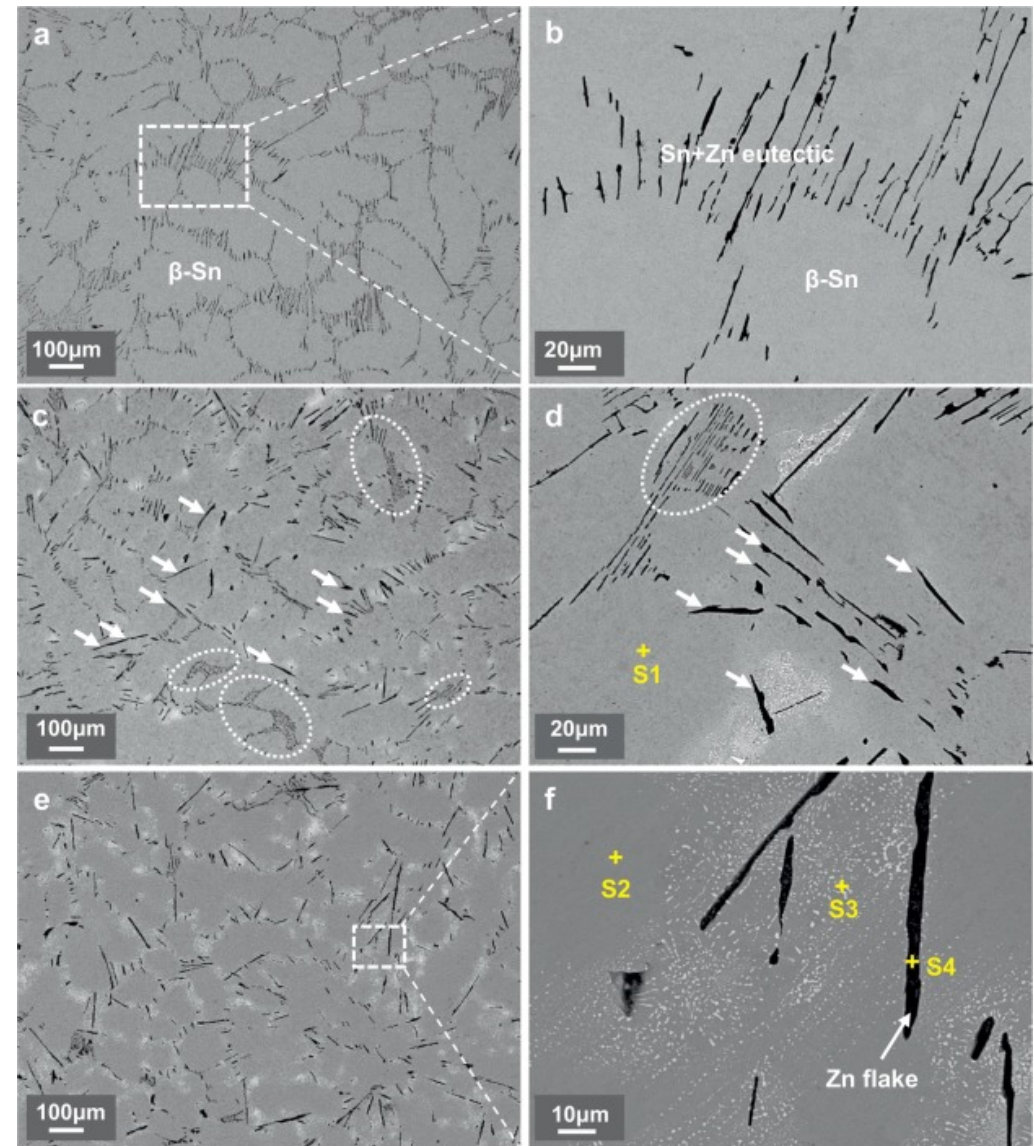

Fig. 2. Backscattered SEM micrographs showing the solidification microstructure of (a, b) Sn3Zn, (c, d) Sn-3Zn-1Bi, and (e, f) Sn-3Zn-5Bi alloy.
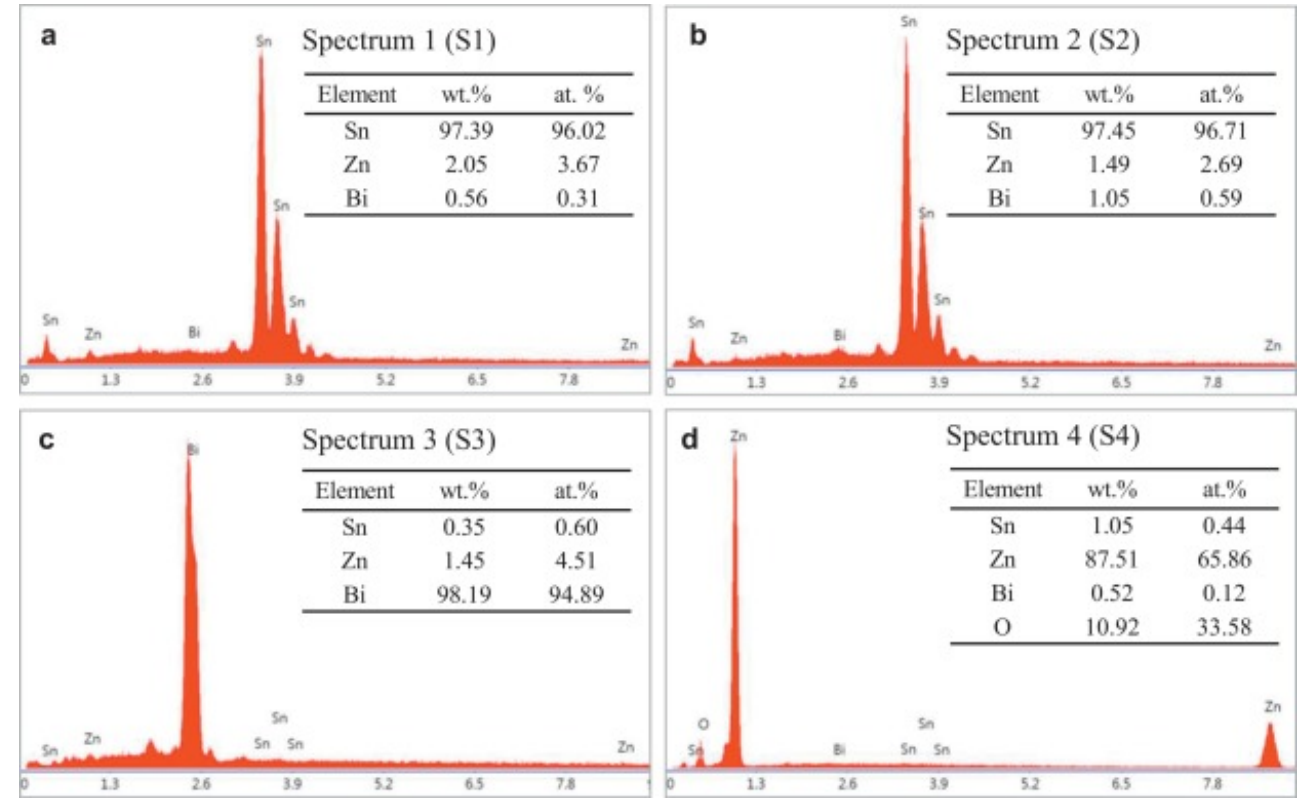

Fig. 3. EDS point analysis on $(a, b)$ matrix phase, (c) white phase, and (d) black phase of the Sn-Zn-Bi alloys, corresponding to the spectrums in Fig. 2. 
Fig. 4 shows the XRD profiles of the as-cast $\mathrm{Sn}-3 \mathrm{Zn}, \mathrm{Sn}-3 \mathrm{Zn}-1 \mathrm{Bi}$, and $\mathrm{Sn}-3 \mathrm{Zn}-5 \mathrm{Bi}$ alloys. It is further confirmed that the $\mathrm{Sn}-3 \mathrm{Zn}$ alloy comprised two phases: a body centered tetragonal $\beta$-Sn matrix phase and a second phase of hexagonal Zn. The Sn-3Zn-5Bi alloy was signified as $\beta$-Sn phase, hexagonal Zn-rich phase, and Bi precipitates. Due to less Bi phase in Sn-3Zn-1Bi, no Bi peaks were identified.

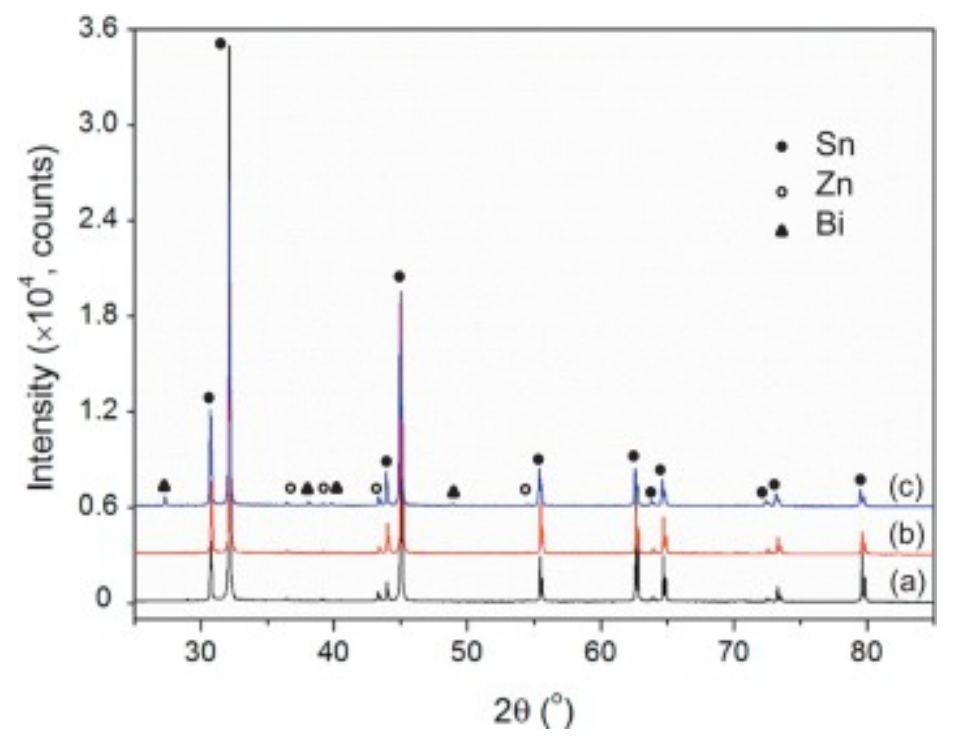

Fig. 4. XRD patterns for the as-cast (a) Sn-3Zn, (b) Sn-3Zn-1Bi, and (c) Sn-3Zn-5Bi alloys.

Modification of $\mathrm{Bi}$ on the solidification microstructure can be understood through the solidification path from the equilibrium phase diagrams, as shown in Fig. 5. The Sn-3Zn alloy was solidified as a hypoeutectic alloy, following the phase transformation: $\mathrm{L} \rightarrow \mathrm{L}+$ primary $\beta$ $\mathrm{Sn} \rightarrow$ primary $\beta-\mathrm{Sn}+$ Eutectic $(\mathrm{Sn}+\mathrm{Zn})$. The microstructure comprised globular primary $\beta$-Sn phase and normal Sn-Zn eutectics, appearing in the form of well aligned fine needle-like $\mathrm{Zn}$ rich precipitates being alternatively distributed in the $\mathrm{Sn}$ matrix. When 1 and $5 \mathrm{wt} \% \mathrm{Bi}$ were added, the practical solidification follows phase transformation: $\mathrm{L} \rightarrow \mathrm{L}+$ primary $\beta-\mathrm{Sn} \rightarrow$ primary $\beta$-Sn + Eutectic $(\mathrm{Sn}+\mathrm{Zn}) \rightarrow$ primary $\beta$-Sn + Eutectic $(\mathrm{Sn}+\mathrm{Zn})+$ Bi precipitates. Both fine needle-like $\mathrm{Zn}$-rich precipitates and coarse $\mathrm{Zn}$-rich flakes were observed, whereas the fraction of fine $\mathrm{Zn}$-rich needles appeared to be less in the Sn-3Zn-5Bi alloy than that in the Sn$3 Z n-1 B i$ alloy. Similar phenomena were reported in previous research [22] [23,24], in which the $\mathrm{Sn}-\mathrm{Zn}$ eutectic turned out to exhibit two kinds of morphologies: the normal Sn-Zn eutectic with fine Zn-rich needles formed alternatively; and the irregular Sn-Zn eutectic with misaligned coarse thick Zn-rich flakes. 

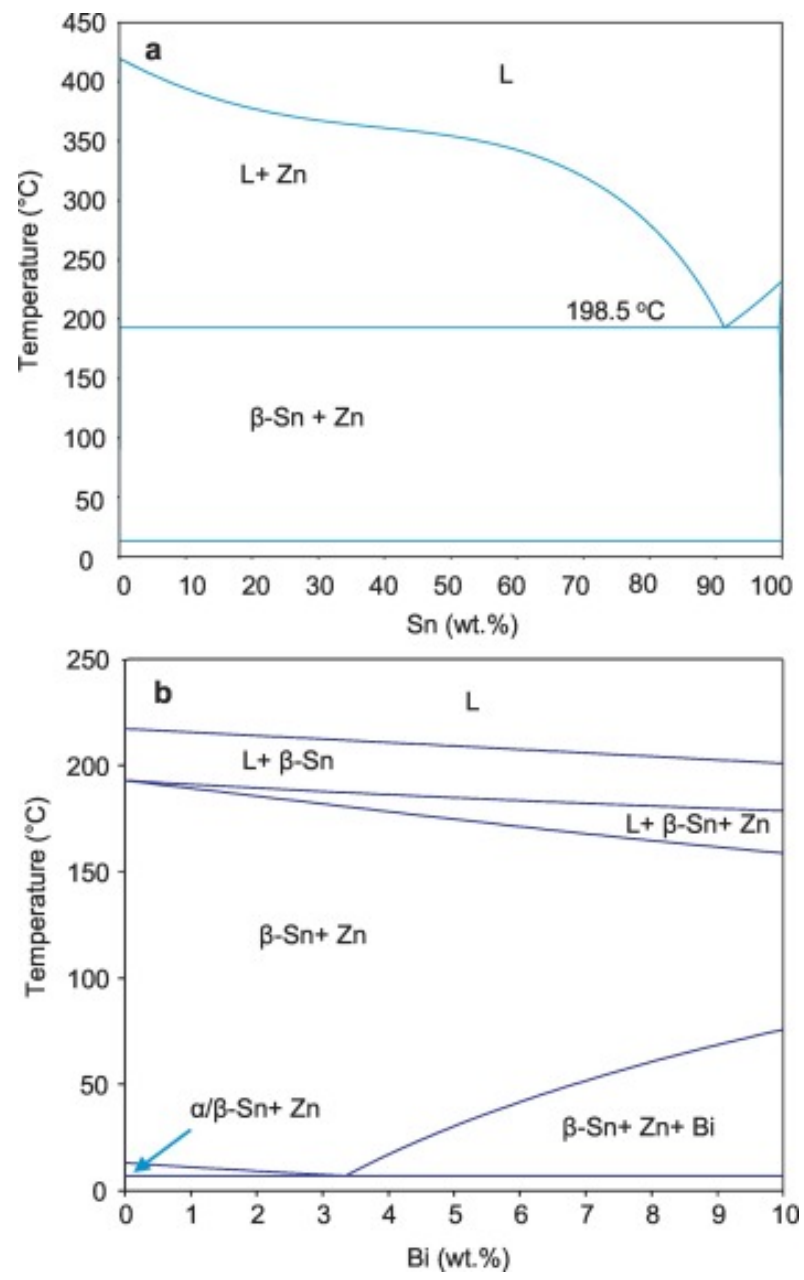

Fig. 5. Equilibrium phase diagram of (a) Sn-Zn, and (b) Sn-3Zn-xBi calculated using Panda.

Difference between the morphology, distribution, and size of Zn-rich phase in hypoeutectic Sn$3 \mathrm{Zn}$ alloy and $\mathrm{Sn}-\mathrm{Zn}-\mathrm{Bi}$ alloy was ascribed to the Bi addition which is a kind of surface-active elements [25]. On one hand, EDS point analysis on Sn matrix (spectrum 1 and 2 in Fig. 2) confirmed the Bi solution into the Sn matrix. Bi alloying element could dissolve into the eutectic structure and thus probably cause change in the lattice parameters of $\mathrm{Sn}$ and $\mathrm{Zn}$, and subsequently an increase in entropy of solution, which may result in the morphological change of the Sn-Zn eutectic from well aligned Zn-rich needles to irregular coarse Zn-rich flakes [22]. During the solidification process, the initially solidified $\mathrm{Sn}-\mathrm{Zn}$ eutectic regions with low Bi solute concentrations formed a normal morphology and then the residual liquid with a greater Bi solute content solidified to become the irregular eutectic structure with coarse $\mathrm{Zn}$-rich flake at lower temperature. This was then followed by Bi precipitation in the form of Bi particles in the vicinity of $\mathrm{Zn}$-rich phase (Fig. $2 \mathrm{~d}$ and $\mathrm{f}$ ). $5 \mathrm{wt} \% \mathrm{Bi}$ alloying was abundant enough in the liquids, the front liquid of the primary solidified $\mathrm{Sn}$ had a large quantity of Bi solutes, which consequently generated more irregular $\mathrm{Sn}-\mathrm{Zn}$ eutectic regions with coarse $\mathrm{Zn}$-rich flakes, resulting in the absence of the normal Sn-Zn eutectic structure in the Sn-3Zn-5Bi alloy. On the other hand, Bi addition further lowered the melting temperature [26]. When solidified, the higher melting point element, Zn, was solidified first, that is, the Zn-rich phase formed earlier, which offered longer time for $\mathrm{Zn}$-rich phase to grow thicker to minimize the surface free energy, resulting in large $\mathrm{Zn}$-rich phase. 


\subsection{Microstructural Evolution Subjected to Rolling}

\subsubsection{Evolution of Primary $\beta$-Sn Phase, Eutectics and Precipitates}

Fig. 6 shows the backscattered SEM micrographs for the microstructure across the longitudinal $(\mathrm{RD}+\mathrm{ND})$ and the transverse (ND + TD) sections of the Sn-3Zn, Sn-3Zn-1Bi, and Sn-3Zn-5Bi alloys. It can be observed that the primary $\beta$-Sn phase and the $\mathrm{Sn}-\mathrm{Zn}$ eutectic regions were severely deformed and elongated along RD. The Zn-rich precipitates and/or Bi aggregates were well aligned to RD (Fig. 6a1, b1, and c1). The intersection dimensions obtained on ND + TD section of primary $\beta$-Sn cells and eutectic regions were remarkably decreased in comparison with the solidification microstructure. The deformed microstructure became much finer (Fig. 6 a2, b2, and c2). Zn-rich precipitates were observed to be distorted and some were fractured. By applying plastic deformation on the samples, the soft Sn matrix flows plastically while the non/less-deformable Zn-rich phase experience a brittle fracture in elastic region. In fact, as results of the rolling processes, some of the brittle $\mathrm{Zn}$-rich phase are mechanically fractured and changed to finer phase.
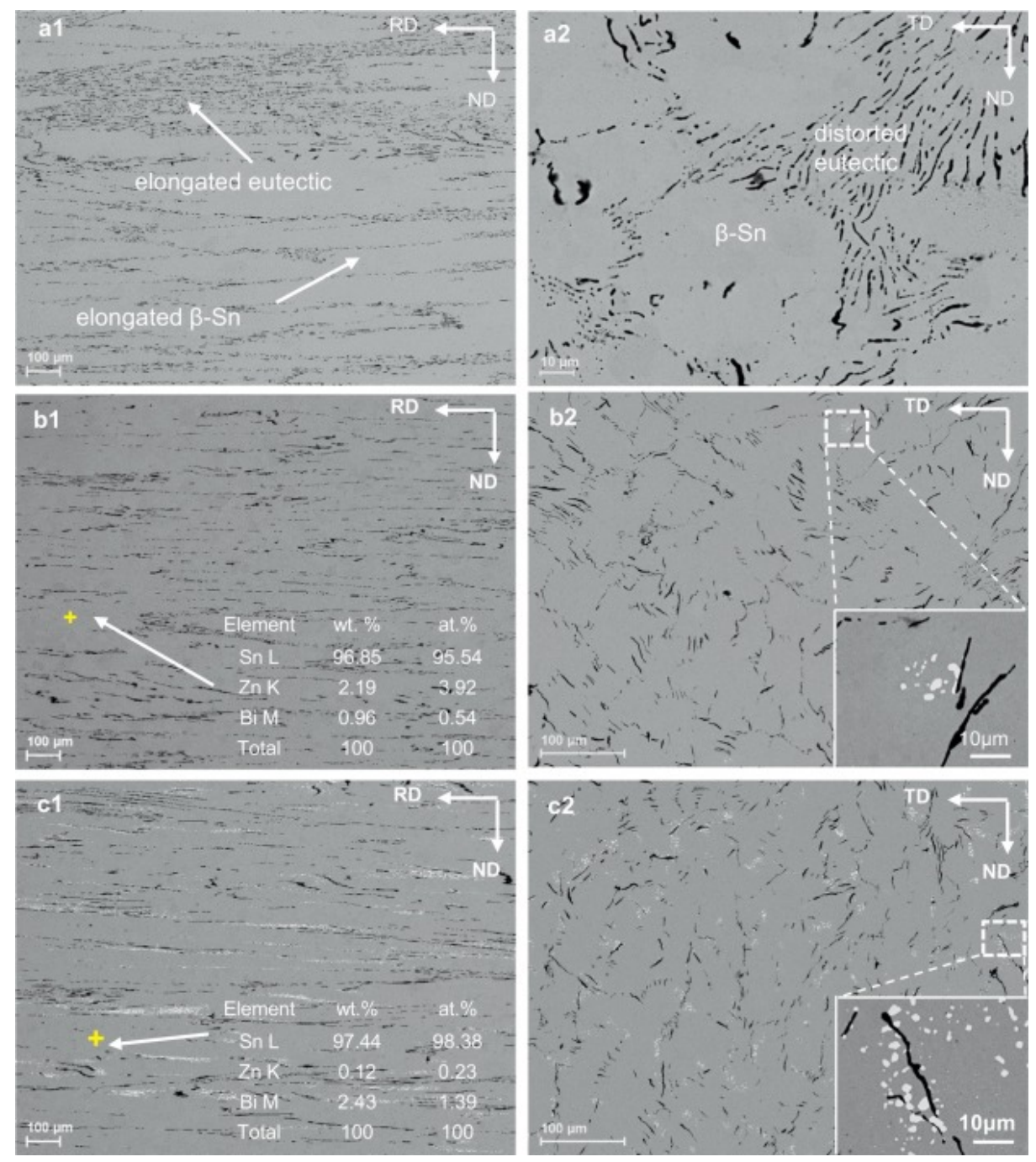
Fig. 6. Backscattered SEM micrographs showing the microstructure on the cross section of TD and RD of as-rolled Sn-Zn-Bi alloys: (a1, a2) Sn-3Zn, (b1, b2) Sn-3Zn-1Bi, and (c1, c2) Sn3Zn-5Bi.

It is well known that fiber-like phases play a main role as stress concentration and crack initiation sites, and therefore noticeably reduce the mechanical properties of the alloys. So, it can be said that modifying the $\mathrm{Zn}$-rich phase is a potential benefit of the rolling process as a secondary mechanical process on cast $\mathrm{Sn}-\mathrm{Zn}$-Bi alloys. The Zn-rich precipitates in the $\mathrm{Sn}-3 \mathrm{Zn}$ $1 \mathrm{Bi}$ and $\mathrm{Sn}-3 \mathrm{Zn}-5 \mathrm{Bi}$ alloys were more homogeneous than that in the Sn-3Zn alloy, which was ascribed to more uniform distribution of the Zn-rich precipitates in the corresponding solidification microstructure. The improved uniformity of cast alloys during rolling is due to the flow of the alloy under the applied shear and compressive forces, resulting in de-clustering of the Zn-rich phase.

It is noted that, after rolling, the distribution of Bi aggregates appeared to be sparser, whereas the size of the individual Bi particles became larger (Fig. $6 \mathrm{~b} 2 \& \mathrm{c} 2$ vs. Fig. 2e\& f). This phenomenon was believed to be associated with the dissolution of $\mathrm{Bi}$ into $\mathrm{Sn}$ matrix and reassembling of the small Bi particles into a bigger one under the rolling stress [27,28,29]. In fact, the dissolution of Bi during rolling was evidenced by the EDS analysis on rolled Sn-3Zn$1 \mathrm{Bi}$ and $\mathrm{Sn}-3 \mathrm{Zn}-5 \mathrm{Bi}$ : the contents of Bi alloying were measured to be largely increased from $0.56 \mathrm{wt} \%$ (as-cast) to $0.96 \mathrm{wt} \%$ (as-rolled) for $\mathrm{Sn}-3 \mathrm{Zn}-1 \mathrm{Bi}$ and from $1.05 \mathrm{wt} \%$ (as-cast) to $2.43 \mathrm{wt} \%$ (as-rolled) for Sn-3Zn-5Bi, as shown in Fig. 3 and Fig. 6b1\& c1.

\subsubsection{Grain Refinement}

Fig. 7 presents the EBSD maps and diagram showing the microstructure and grain boundary misorientations distribution on the RD-ND section of the rolled Sn-3Zn specimen. High-angle grain boundaries (HAGBs) with misorientation angles being larger than $15^{\circ}$ are presented with black solid lines. Low-angle grain boundaries (LAGBs) with misorientation angles being in the range of $2-15^{\circ}$ are illustrated with light-blue solid lines. From Fig. $7 \mathrm{a}$, the structure showed partially recrystallized grain morphology. Inhomogeneous grains with a wide grain size range presented, possessing large grain sizes being in the range of 50-120 $\mu \mathrm{m}$ and small ones being several microns. The large grains were originated from the pre-rolled primary Sn phase regions, whereas the small grains were found to be located in the eutectic regions and/or in the vicinity of the Zn-rich precipitates, as highlighted with yellow lines, for instance. Full inspection of the $\mathrm{Sn}-\mathrm{Zn}$ eutectic area marked with rectangular revealed that majority of the grains within the region exhibited small-sized equiaxed morphologies with grains size being less than $10 \mu \mathrm{m}$ (Fig. 7b) and a large fraction of low-angle grain boundaries formed. This indicated that the Sn- $\mathrm{Zn}$ eutectic sites or Zn-rich precipitate sites were beneficial to accumulation of strains or dislocations and consequently benefited formation of smaller grains. It is seen from Fig. $7 \mathrm{~b}$ that the distribution of grain boundary misorientations suggested a relatively uniform misorientations distribution. Low-angle grain boundaries $\left(2-15^{\circ}\right)$ took up about $12 \%$ of the total grain boundaries. The average misorientation angle was measured to be approximately $50.3^{\circ}$. 



Fig. 7. (a) EBSD IQ + IPF, (b) EBSD phase map, and (c) distribution of grain boundary misorientations for the rolled Sn-3Zn alloy extracted on the RD-ND section. LAGBs: low-angle grain boundaries (2-15o).

Fig. 8 shows the EBSD maps and grain boundary misorientations distribution for the rolled Sn3Zn-1Bi (Fig. 8a and b) and Sn-3Zn-5Bi (Fig. 8c, d, and e). The maps were extracted from the RD-ND sections. With $1 \mathrm{wt} \% \mathrm{Bi}$ addition, the microstructure was characterized as relatively homogeneous grains (Fig. 8a). Equiaxed grains, defined as those with grain shape aspect ratio larger than 0.6 , rather than elongated grains largely presented. The grain sizes covered a relatively small range from several microns to $\sim 50 \mu \mathrm{m}$. Still, small grains tended to form in the vicinity of $\mathrm{Sn}-\mathrm{Zn}$ eutectic regions or $\mathrm{Zn}$ precipitate sites (circled areas), further indicating that these sites favored the formation of smaller grains. It was measured that low-angle grain boundaries accounted for $\sim 8 \%$ of total grain boundaries, which was lower than that in rolled Sn-3Zn alloy, suggesting a more complete recrystallization (Fig. 7b). With further increasing Bi content to $5 \mathrm{wt} \%$, the microstructure became much finer with highly homogeneous equiaxed grains, being approximately $10-20 \mu \mathrm{m}$ in grain size (Fig. 8c). Additionally, it is noted that extremely small grains $(<5 \mu \mathrm{m})$ appeared in the region highlighted with white lines. This region contained large amounts of Bi particles (Fig. 8d), further indicating that Bi particle-enriched area could benefit the formation of small grains. Also, the fraction of low-angle grain boundaries $\left(2-15^{\circ}\right)$ further decreased to $\sim 4 \%$ (Fig. 8e). 

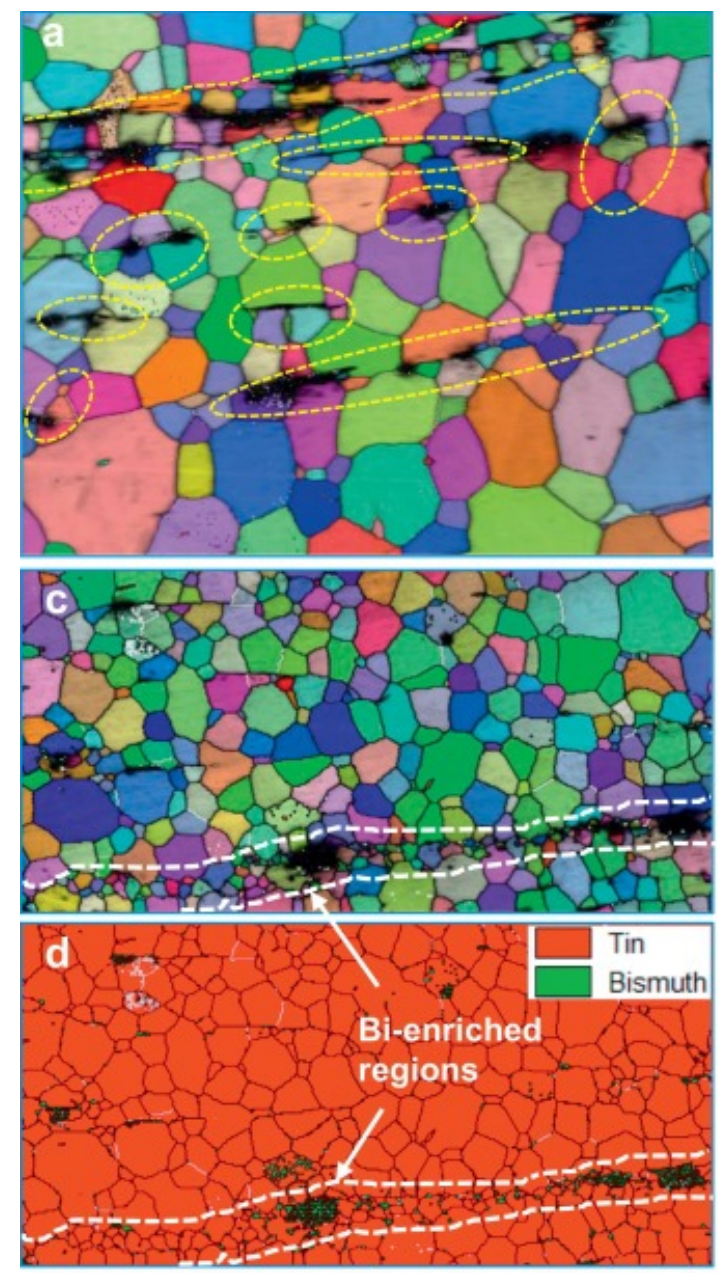
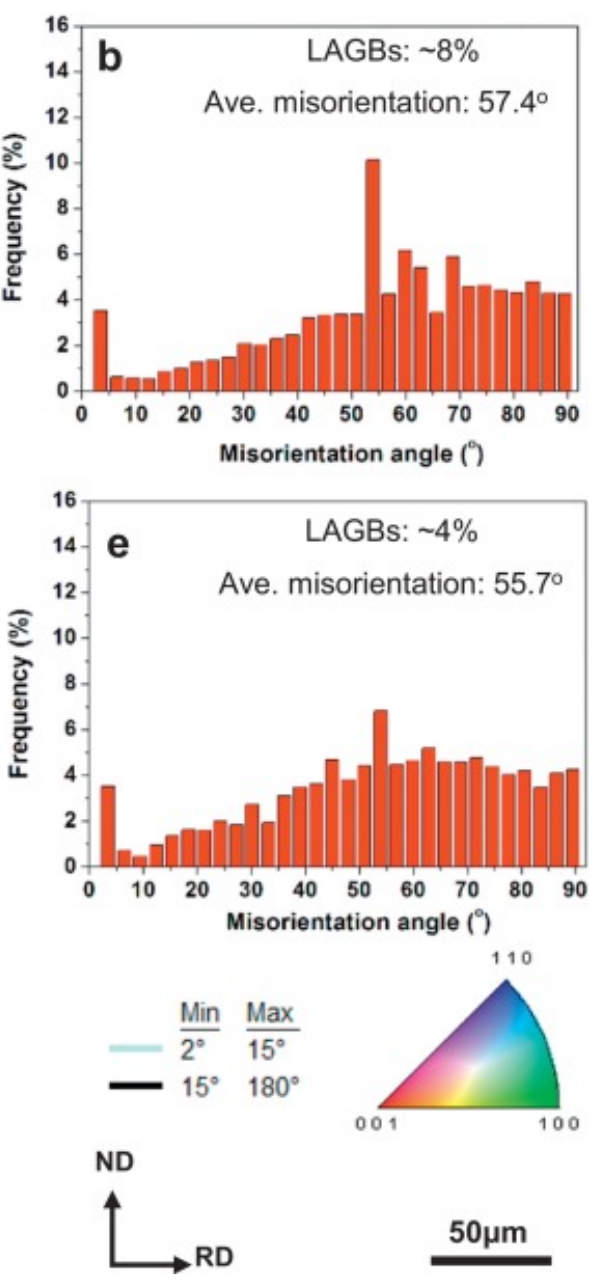

Fig. 8. EBSD IQ + IPF maps, phase map, and diagrams showing the microstructure and the distribution of grain boundary misorientations for the rolled (a, b) Sn-3Zn-1Bi and (c, d, e) Sn3Zn-5Bi alloy. LAGBs: low-angle grain boundaries (2-15o).

Fig. 9 shows the EBSD boundary maps and grain distribution attained on the ND-TD section of the Sn-3Zn, Sn-3Zn-1Bi and Sn-3Zn-5Bi alloys. Grains with different sizes were highlighted with different colors (blue: $3-10 \mu \mathrm{m}$; white: $10-30 \mu \mathrm{m}$; and red: $>30 \mu \mathrm{m}$ ). The misorentations angle from 2 to $180^{\circ}$ were illustrated in the legend. The grains with grain size being larger than $3 \mu \mathrm{m}$ were taken into consideration for statistically grain size measurement. The structure of rolled Sn-3Zn exhibited bimodal grain distribution (Fig. 9a). It was measured that in the Sn$3 Z n$ alloy the grains with grain size being larger than $30 \mu \mathrm{m}$ took up most of the area, $66.9 \%$ in area fraction, and the area fraction of small grains with grain size being less than $10 \mu \mathrm{m}$ just accounted for $4.9 \%$. However, in the Sn-Zn-Bi alloys, the microstructure had uniform grains. In specific, when $1 \mathrm{wt} \% \mathrm{Bi}$ was added, the number of small grains with grain size being less than $10 \mu \mathrm{m}$ was increased, with the area fraction twice of that for Sn-3Zn, 11.4\%, whereas the number of large grains with grain size being larger than $30 \mu \mathrm{m}$ was dramatically decreased, with area fraction dropping to $24.7 \%$. Further adding $5 \mathrm{wt} \%$ Bi led to majority of smaller equiaxed and homogeneous grains, no more grains being larger than $30 \mu \mathrm{m}$ was observed. The small grains being less than $10 \mu \mathrm{m}$ took up $20.1 \%$ of the whole area. In average, the grain size 
was measured to be around $44.3 \mu \mathrm{m}, 22.8 \mu \mathrm{m}$, and $15.3 \mu \mathrm{m}$ for the Sn-3Zn, Sn-3Zn-1Bi, and Sn-3Zn-5Bi, respectively (Fig. 9d, e and f).
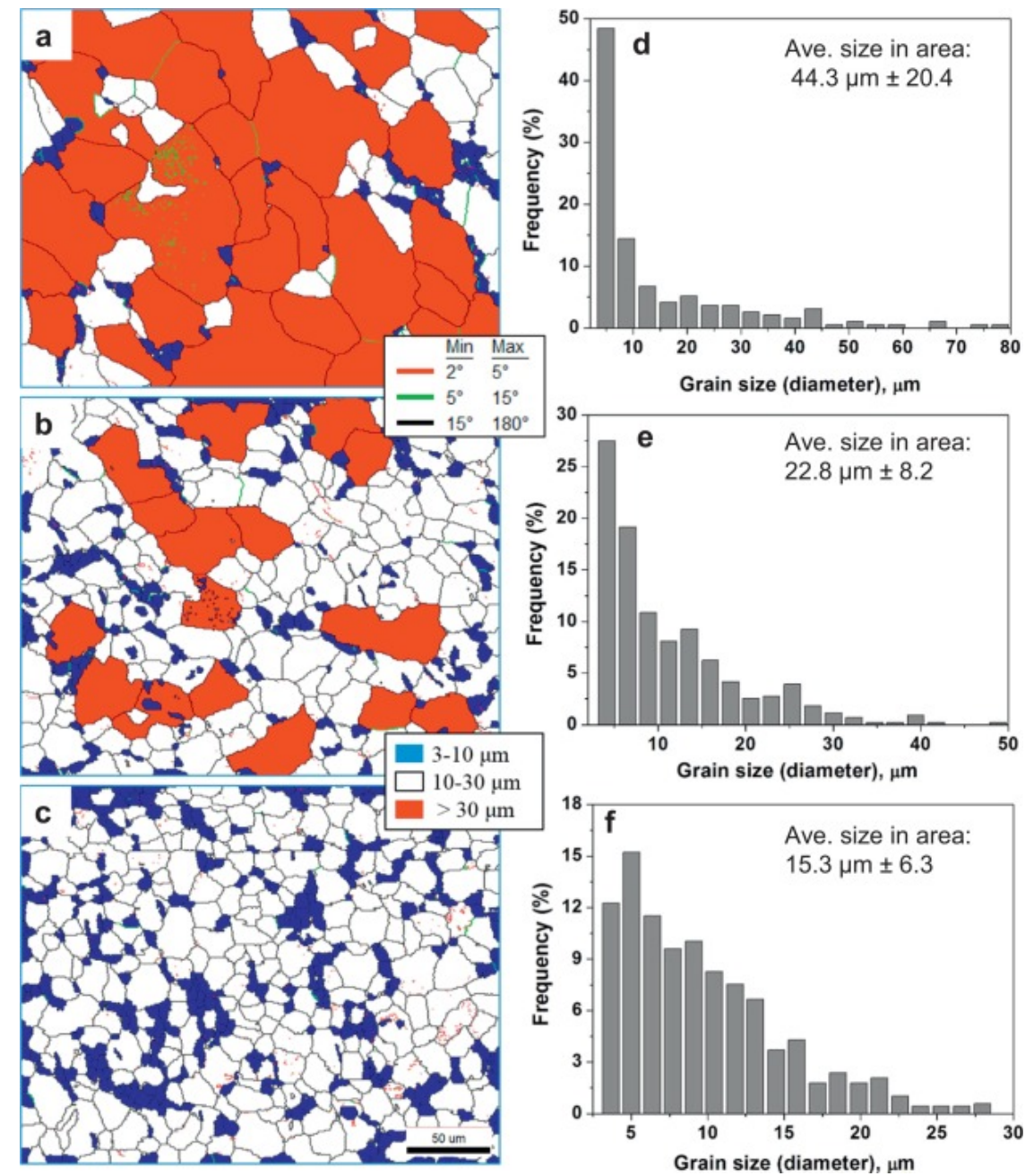

Fig. 9. The EBSD boundary maps and grain distribution diagrams obtained on ND + TD section of the rolled (a, d) Sn-3Zn, (b, e) Sn-3Zn-1Bi, and (c, f) Sn-3Zn-5Bi alloy.

The grain refinement and grain boundaries evolution during rolling could be closely related to dislocation activities and dynamic recrystallization (DRX) behavior. DRX refers to the occurrence of recrystallization during deformation. In the process of DRX, accumulation of dislocations by straining is often accompanied by nucleation and growth of the newly formed dislocation-free grains. Same as static recrystallization (SRX) that usually takes place during annealing, DRX is a process of energy-releasing, which counteracts the energy-storing process associated with multiplication of dislocations and sub-boundaries produced during straining.

It has been well documented that conventional dynamic recrystallization (often referred to as discontinuous dynamic recrystallization, dDRX) takes place during straining as long as the working temperature is above $0.5 \mathrm{Tm}[30,31,32]$. In our case, the ambient rolling was considered as hot working because the processing temperature, $293 \mathrm{~K}$, is larger than $0.5 \mathrm{Tm}$ [19], in addition to the dislocations accumulation and formation of sub-grains, the DRX was thus the most common feature during deformation. This was, in fact, well supported by the fact that the microstructure after rolling presented typical hot-processing structures with the grains being 
partially or fully recrystallized. In general, $\mathrm{dDRX}$ is considered as a two-step process: first the nucleation of new grains, and then growth. In these materials subjected to dDRX, the dislocation density increases to a high level and eventually some of the local difference in density reach a high enough level to permit the nucleation of new grains. Then, this followed by the long-range migration of high angle grain boundaries. Factors affecting the process of nucleation and/or growth will influence the final grain configuration. Second phase including Zn-rich precipitates and Bi particles, combined with Bi solutes were believed to affect the two processes (nucleation and growth) of DRX and consequently be responsible for the different grain configuration in terms of the grain size and homogeneity.

It has been suggested that large $(>1 \mu \mathrm{m})$ second phase particles, especially those widely spaced particles could promote dynamic recrystallization via the mechanism of particle-stimulated nucleation (PSN) [33, 34, 35]. This was based on the explanation that the enforced strain gradient in the vicinity of a less-deformable particle creates a region of high-density dislocations and large orientation gradient (particle deformation zone, or PDZ), which is an ideal site for the development of a recrystallization nucleus. In the Sn-3Zn alloy, the Zn-rich precipitates acting as nucleation sites, can lead to large amounts of recrystallized nuclei in the Sn-Zn eutectic regions. This facilitates the initiation of recrystallization. On the other hand, when recrystallized nuclei grow the Zn-rich precipitates can act as the obstacles to hinter the growth of the recrystallized grains. Many small-sized recrystallized grains consequently formed in the regions of $\mathrm{Sn}-\mathrm{Zn}$ eutectics. On the contrary, the original primary $\beta$-Sn regions lack nucleation sites such as particles and/or high density of dislocations, thus, impeding the initiation of recrystallization. Moreover, mobility of boundaries (growth) of the recrystallized grains forward cross the primary $\beta$-Sn regions can easily occur as no particles acting as barriers will prevent the boundaries from moving, which as a result causes relatively large grains in the particle-free areas.

When Bi was added, as discussed before, Bi solutes in one aspect cause homogeneously distributed Zn-rich precipitates and Bi second phase particles, which in one hand offers more sites for nucleation, and on the other hand, provides more barriers to hinter the growth of recrystallized grains. This boosts the effect of the second phase particles on reduction of recrystallized grain size. In other aspects, $\mathrm{Bi}$ has relative amount of solubility in $\mathrm{Sn}$ at room temperature ( $<1.5 \mathrm{wt} \%$ [25] [36]), which was also evidenced by the EDS results (Fig. 3). The role of solutes in decreasing the rate of grain boundary motion through solute drag has been largely discussed in previous research $[37,38,39,40]$, which is based on the idea that a moving boundary drags an atmosphere of solute atoms that exerts a retarding force on it. The retardation of grain boundary mobility in return impedes the growth process, decreasing the recrystallized grain size. Moreover, the effect of solutes on the nucleation of DRX was introduced by Cram et al. [41], which further enriched the understanding of retardation effect of DRX. This is based on the consideration that solute atoms may segregate to the dislocations in the sub-grain boundary and their binding with the vacancies that mediate the sub-grain motion retards the kinetics of DRX. Based on these, it is understandable that with Bi addition the grain size of rolled Sn-Zn-Bi alloys became much finer, reaching the smallest value in the case of Sn-3Zn5Bi alloy. 


\subsection{Correlation between the Microstructure and Mechanical Properties}

Fig. 10 presents the tensile results of the rolled $\mathrm{Sn}-\mathrm{Zn}-\mathrm{Bi}$ alloys. The stress-strain curves indicated that strain softening occurred in all cases when the alloys were subjected to tensile stress. This was ascribed to the high-rate annihilation (recovery) of dislocations and dynamic recrystallization under tensile stress. The $\beta$-Sn crystal is known to have a tetragonal distortion of the diamond crystal structure with two atoms per primitive cell. There are about 32 different slip systems in $\beta$-Sn and at least five slip systems: (110)[-111]/2, (101)[010], (101)[11-1]/2, (121)[-101], and (121)[1-11]/2 are energetically preferable [42, 43]. When the alloys are deformed under tensile stress, dislocation activities including dislocation multiplication and annihilation will predominate the deformation, a competition of the dislocation multiplication which resulting in hardening and the dislocation annihilation contributing to softening will take place. If the rate of dislocation annihilation is higher than that of dislocation multiplication, the strain softening will be attained. Inversely, the strain hardening will exhibit. As mentioned before, the tensile test which was carried out at $293 \mathrm{~K}$ was a hot working processing. The dynamic recovery rate is sufficiently high to counteract the hardening effect caused by dislocation accumulation. Moreover, the newly formed recrystallized grains appearing during straining could produce softening, decreasing the work hardening rate, as a result contribute to the softening phenomenon.
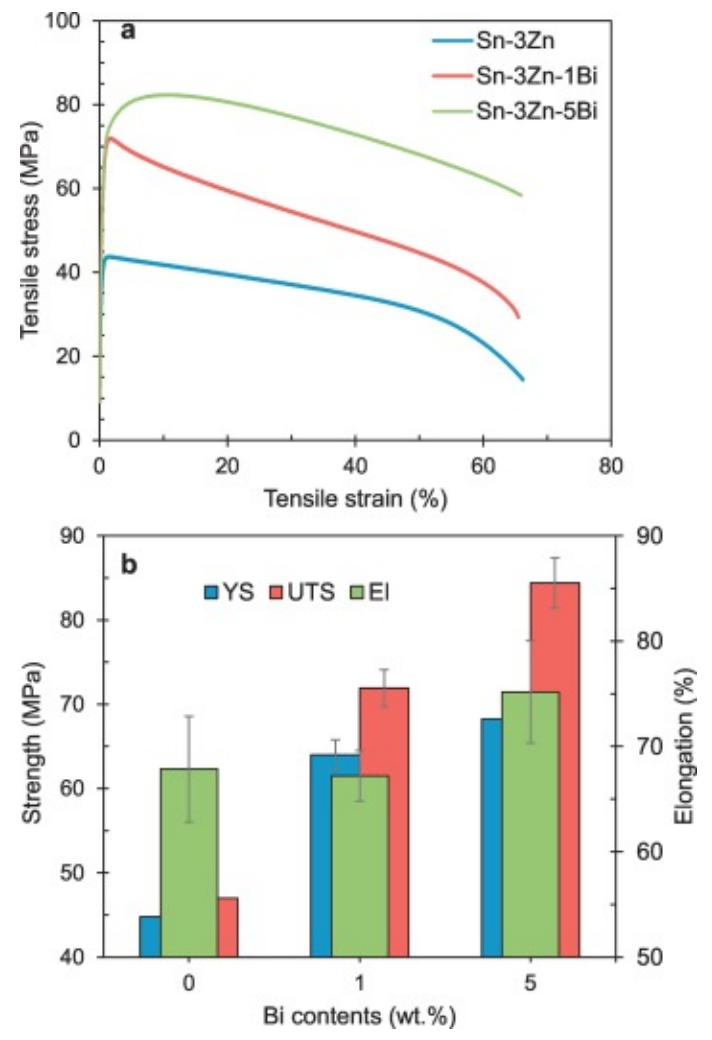

Fig. 10. (a) Tensile stress-strain curves for rolled Sn-Zn-Bi alloys, and (b) the effect of Bi content on the tensile properties of the rolled $\mathrm{Sn}-3 \mathrm{Zn}$ alloy.

From Fig. 10b, it was obvious that Bi not only caused a significant increase in the strength but also improved the elongation of Sn-3Zn alloys. Specifically, the UTS and yield strength of the Sn-3Zn alloy was 47.0 MPa and 44.8 MPa, respectively. With $1 \mathrm{wt} \% \mathrm{Bi}$ addition, the UTS and 
yield strength was dramatically increased to $71.9 \mathrm{MPa}$ and $64.0 \mathrm{MPa}$, respectively. When $\mathrm{Bi}$ was further increased to $5 \mathrm{wt} \%$, the UTS and yield strength was further increased to $84.4 \mathrm{MPa}$ and 68.3 MPa, respectively. The elongation of Sn-3Zn and Sn-3Zn-1Bi showed a similar value around $67.5 \%$, whereas $5 \mathrm{wt} \% \mathrm{Bi}$ addition increased the elongation to $75.2 \%$. The improvement in both strength and ductility was closely dependent on the microstructure variation, mainly involving the solutes, second phases, and grain boundaries.

Elements in solid solution usually strengthen crystals. This effect is mainly attributable to interaction of the solute atoms with the dilatational stress filed around dislocations, which makes dislocation motion more difficult. As a result, the strength, especially, the yield strength of alloys is enhanced. The maximum solubility of $\mathrm{Zn}$ in $\mathrm{Sn}$ is around $0.33 \mathrm{wt} \%$ at $198.5^{\circ} \mathrm{C}$ and at room temperature it is around $0.14 \mathrm{wt} \%$ [24], suggesting that the solubility is very limited. The solid solution strengthening from $\mathrm{Zn}$ solutes is thus believed to be very minimal. However, Bi has relative solubility in $\mathrm{Sn}(\sim 1.5 \mathrm{wt} \%$ at room temperature $[25,36])$. In fact, EDS analysis on rolled Sn-Zn-Bi (Fig. 6) has confirmed the increased Bi solubility in Sn, from $0.96 \mathrm{wt} \%$ to $2.43 \mathrm{wt} \%$ with Bi content increasing from $1 \mathrm{wt} \%$ to $5 \mathrm{wt} \%$. Therefore, Bi solid solution strengthening could be an important factor improving strength of the Bi-containing alloys.

Besides, second phase strengthening mechanism operate effectively. The non-deformable Znrich phase and brittle Bi particles are stronger than the soft Sn matrix. These second phases act as barriers for dislocation movement, causing an enhancement of initial strength. The experimental results have confirmed that Bi addition changed the Sn-Zn eutectic morphology, leading to essential microstructural refinement with highly dispersed Zn-rich precipitates [44]. Consequently, more uniformly distributed $\mathrm{Zn}$-rich precipitates enhanced the effectiveness of second phase strengthening. Therefore, the strength of the alloys was increased with increasing Bi content.

Grain boundaries are important obstacles to slip, with finer grain sizes there are more grain boundaries to impede dislocation motion. Therefore, materials with fine grains are stronger than those with large grains. The relationship between yield strength and grain size are often expressed by the Hall-Petch equation $[45,46]: \sigma=\sigma o+\mathrm{kd}-1 / 2$, where $\sigma o$ and $\mathrm{k}$ are constants, and $d$ is the grain size. The grain size was proved to be decreased with increasing Bi content (Fig. 9). For clarity, the relation between the grain size and Bi content was plotted, as shown in Fig. 11. With increasing Bi content, the mean grain size experienced a dramatic decrease (from $44.3 \mu \mathrm{m}$ dropping to $15.3 \mu \mathrm{m})$. The fraction of smaller grains $(<30 \mu \mathrm{m})$ increased considerably. So, the decreased grain size contributes to the increased strength in the Bi-containing alloys. 


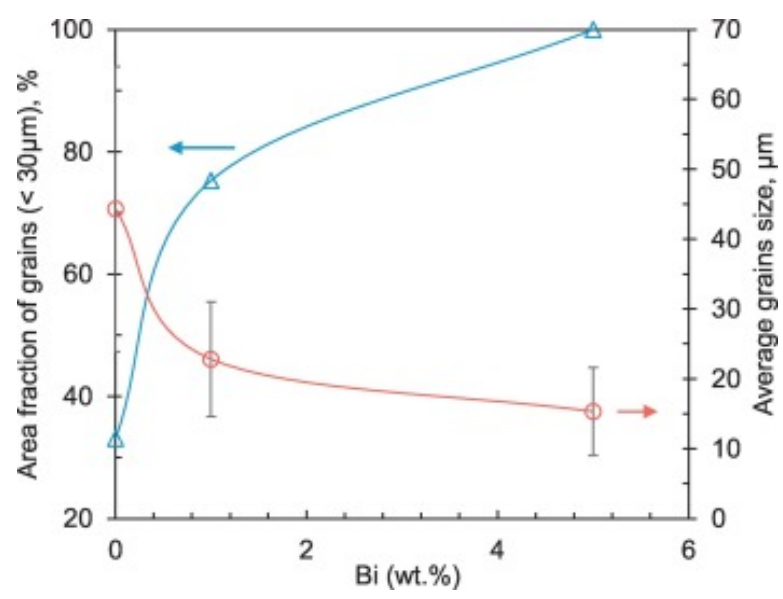

Fig. 11. The effect of Bi content on the grain size evolution of the rolled $\mathrm{Sn}-\mathrm{Zn}-\mathrm{Bi}$ alloys.

It should be noted that the brittle Bi phase was reported to harm the ductility [21]. However, this is not in agreement with the present results. In our case, $5 \mathrm{wt} \% \mathrm{Bi}$ addition possesses a highest elongation ( $75 \%$ ). The superior ductility of rolled $\mathrm{Sn}-3 \mathrm{Zn}-5 \mathrm{Bi}$ was attributable to the ductility-boosting factors: (1) smallest grain size; (2) largest fraction of equiaxed grains; and (3) largest proportion of HAGBs. Fig. 12 shows variation of fraction of equiaxed grains, and grain boundary misorientation angles with $\mathrm{Bi}$ content. The number fraction of the equiaxed grains was increased notably with increasing Bi, from $20.2 \%$ to $37.1 \%$ (Fig. 12a). Also, higher number proportion of HAGBs was obtained in higher Bi-containing alloys (Fig. 12b). Based on these, it is induced that the good ductility of $\mathrm{Sn}-3 \mathrm{Zn}-5 \mathrm{Bi}$ is a result of high proportion of small equiaxed grains and HAGBs.
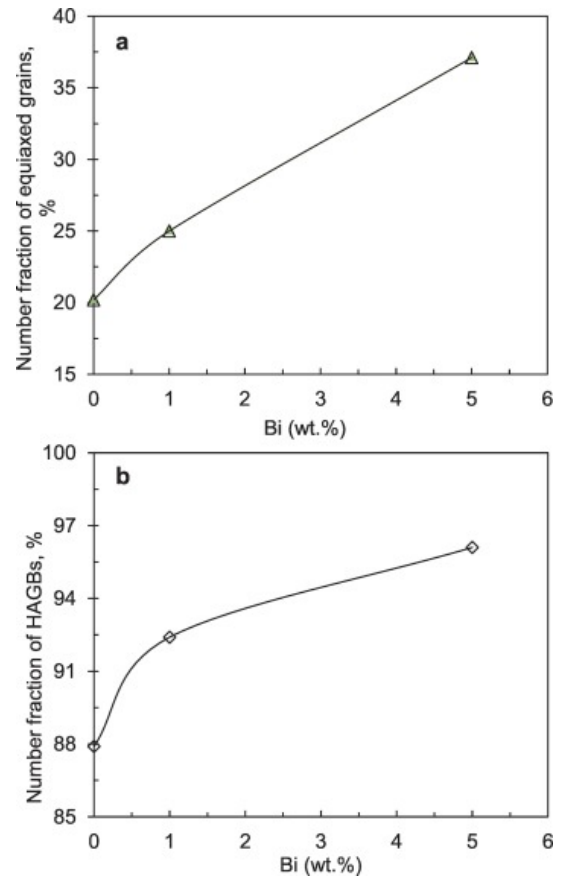

Fig. 12. The effect of Bi content on the fraction of (a) equiaxed grains, and (b) high angle grain boundaries (HAGBs) of the rolled $\mathrm{Sn}-\mathrm{Zn}-\mathrm{Bi}$ alloys. 


\section{Conclusions}

In this work, effects of $\mathrm{Bi}$ on the microstructure and mechanical properties of the Sn-3Zn alloys were investigated under as-cast and as-rolled conditions. Bi can effectively refine the solidification microstructure. It shows that Bi enhances both the strength and ductility of the rolled Sn-3Zn-Bi alloys. Based on observation of the microstructure and tensile results, some conclusions can be drawn as following:

(1) Adding Bi can modify the Sn-Zn eutectic morphology from well-aligned Zn-rich needles to irregular coarse Zn-rich flakes and result in effective refinement of the microstructure.

(2) Zn-rich phase, Bi precipitates, and Bi solutes have significant effects on dynamic recrystallization (DRX) occurring during plastic deformation. This is because second phases on one hand provide more nucleation sites, on the other hand, offer relative obstacles to growth of new crystallized grains. Also, Bi solutes can hinder motion of the new grain boundaries.

(3) Higher Bi content enhances the strength and elongation of the rolled Sn-Zn-Bi alloys. The Sn-3Zn-5Bi alloy achieved superior mechanical properties, with the UTS, yield strength, and elongation of $84.4 \mathrm{MPa}, 68.3 \mathrm{MPa}$, and 75.2\%, respectively, because it possessed most homogenous smallest equiaxed grains combined with largest proportion of HAGBs.

(4) From perspective of decent mechanical properties and ease of casting, $\mathrm{Sn}-\mathrm{Zn}$-Bi alloys are very likely to be prospective substitute for currently used $\mathrm{Pb}$-based materials for the application as cladding materials in detonating and explosive cords.

\section{Acknowledgment}

Financial support from the National Aerospace Technology Exploitation Programme (NATEP) and Chemring Energetics UK [grant number WEAF058] is gratefully acknowledged.

\section{References}

[1] G.E. Brophy Aircraft cockpit canopy United States patent, US 4580745 (1986)

[2] H. Deplante Method and device related to the ejection of a person from an aircraft cockpit or the like United States patent, US 3729154A (1973)

[3] G.A. Noddin, N.J. Mantua Non-rupturing detonating cords. United States patent, US 3311056 (1967)

[4] M.B. Liu, G.R. Liu, K.Y. Lam, Z. Zong. Meshfree particle simulation of the detonation process for high explosives in shaped charge unlined cavity configurations Shock Waves, 12 (6) (2003), pp. 509-520

[5] O. Ayisit The influence of asymmetries in shaped charge performance Int. J. Impact Eng., 35 (2008), pp. 1399-1404 
[6] D.J. Andrew, R.W. Felch, G.A. Noddin Connecting cord United States patent US 2982210A (1961)

[7] Commission of the European Communities Council Directive 96/22/EC Off European Community Legislation (1966) (L125:3)

[8] G. Liu, S. Ji, L. Grechcini, A. Bentley, Z. Fan Microstructure and mechanical properties of $\mathrm{Sn}-\mathrm{Cu}$ alloys for detonating and explosive cords Mater. Sci. Technol. (2017), pp. 1-12

[9] H. Ye, S. Xue, J. Luo, Y. Li Properties and interfacial microstructure of Sn-Zn-Ga solder joint with rare earth Pr addition Mater. Des., 46 (2013), pp. 816-823

[10] X. Zhu, H. Kotadia, S. Xu, H. Lu, S.H. Mannan, C. Bailey, Y.C. Chan Electromigration in Sn-Ag solder thin films under high current density Thin Solid Films, 565 (2014), pp. 193-201

[11] W.R. Osório, J.E. Spinelli, C.R. Afonso, L.C. Peixoto, A. Garcia Microstructure, corrosion behaviour and microhardness of a directionally solidified $\mathrm{Sn}-\mathrm{Cu}$ solder alloy Electrochim. Acta, 56 (24) (2011), pp. 8891-8899

[12] K.W. Moon, W.J. Boettinger, U.R. Kattner, F.S. Biancaniello, C.A. Handwerker Experimental and thermodynamic assessment of $\mathrm{Sn}-\mathrm{Ag}-\mathrm{Cu}$ solder alloys J. Electron. Mater., 29 (10) (2000), pp. 1122-1136

[13] J.A. Graham Reactive products having tin and tin alloy liners and sheaths United States patent, US 5827995A (1998)

[14] S. Rodney, L.H. Barr Tin alloy sheath material for explosive-pyrotechnic linear products United States patent, US 5333550 (1994)

[15] Y.S. Huang, J.T. Li, J.B. Liu, H. Su, W.T. Wang, N. Huang Non-lead metal material and application of non-lead metal material to cord type initiating explosive devices, CN 102560194A (2012)

[16] M. Hammam, F.S. Allah, E.S. Gouda, Y. El Gendy, H.A. Aziz Structure and properties of Sn-9Zn lead-free solder alloy with heat treatment Engineering, 2 (3) (2010), pp. 172-178

[17] X. Wei, H. Huang, L. Zhou, M. Zhang, X. Liu On the advantages of using a hypoeutectic $\mathrm{Sn}-\mathrm{Zn}$ as lead-free solder material Mater. Lett., 61 (3) (2007), pp. 655-658

[18] K. Suganuma Advance in lead-free electronics soldering Curr. Opin. Solid State Mater. Sci., 5 (2001), pp. 55-64

[19] K. Suganuma, K.S. Kim Sn-Zn low temperature solder J. Mater. Sci. Mater. Electron., 18 (1-3) (2007), pp. 121-127

[20] Y.S. Kim, K.S. Kim, C.W. Hwang, K. Suganuma Effect of composition and cooling rate on microstructure and tensile properties of $\mathrm{Sn}-\mathrm{Zn}-\mathrm{Bi}$ alloys

J. Alloys Compd., 352 (1) (2003), pp. 237-245 
[21] A.A. El-Daly, H.A. Hashem, N. Radwan, F. El-Tantawy, T.R. Dalloul, N.A. Mansour, H.M. Abd-Elmoniem, E.H. Lotfy. Robust effects of bi doping on microstructure development and mechanical properties of hypoeutectic Sn-6.5Zn solder alloy. J. Mater. Sci. Mater. Electron., 27 (3) (2016), pp. 2950-2962

[22] J.M. Song, Z.M. Wu Variable eutectic temperature caused by inhomogeneous solute distribution in Sn-Zn system Scr. Mater., 54 (8) (2006), pp. 1479-1483

[23] J.-C. Liu, G. Zhang, Z.-H. Wang, J.-S. Ma, K. Suganuma Thermal property, wettability and interfacial characterization of novel $\mathrm{Sn}-\mathrm{Zn}$-Bi-In alloys as low-temperature lead-free solders Mater. Des., 84 (2015), pp. 331-339

[24] M.M. Billah, K.M. Shorowordi, A. Sharif Effect of micron size Ni particle addition in Sn$8 \mathrm{Zn}-3 \mathrm{Bi}$ lead-free solder alloy on the microstructure, thermal and mechanical properties $\mathrm{J}$. Alloys Compd., 585 (2014), pp. 32-39

[25] L.C. Prasad, A. Mikula Role of surface properties on the wettability of Sn-Pb-Bi solder alloys J. Alloys Compd., 282 (1) (1999), pp. 279-285

[26] Y.S. Kim, K.S. Kim, C.W. Hwang, K. Suganuma Effect of composition and cooling rate on microstructure and tensile properties of Sn-Zn-Bi alloys J. Alloys Compd., 352 (1) (2003), pp. 237-245

[27] J. Lendvai, H.J. Gudladt, V. Gerold The deformation-induced dissolution of $\delta 1$ precipitates in Al-Li alloys Scr. Metall., 22 (1988), pp. 1755-1760

[28] C. Watanabe, R. Monzen, K. Tazaki Effects of Al3Sc particle size and precipitate-free zones on fatigue behaviour and dislocation structure of an aged al-mg-Sc alloy Int. J. Fatigue, 30 (2008), pp. 635-641

[29] M. Song, K. Du, Z.Y. Huang, H. Huang, Z.R. Nie, H.Q. Ye Deformation-induced dissolution and growth of precipitates in an Al-Mg-Er alloy during high-cycle fatigue Acta Mater., 81 (2014), pp. 409-419

[30] C.M. Sellars Recrystallization of metals during hot deformation Phil. Trans. R. Soc. A, 288 (1978), pp. 147-158

[31] H. Mecking, G. Gottstein Recovery and recrystallization during deformation F. Haessner (Ed.), Recrystallization of Metallic Materials. Stuttgart: Dr, Riederer-Verlag, Gmbh (1978), pp. 195-222

[32] H.J. McQueen, J.J. Jonas Recovery and recrystallization during high temperature deformation Treatise on Materials Science and Technology, Vol. 6, New York: Academic Press (1975), pp. 393-493

[33] F.J. Humphreys The nucleation of recrystallization at second phase particles in deformed aluminium Acta Metall., 25 (11) (1977), pp. 1323-1344 
[34] R.D. Doherty, D.A. Hughes, F.J. Humphreys, J.J. Jonas, D. Juul Jensen, M.E. Kassner, W.E. King, T.R. McNelley, H.J. McQueen, A.D. Rollett Current issues in recrystallization: a review Mater. Sci. Eng. A, 238 (2) (1997), pp. 219-274

[35] R.A. Shahani, T.W. Clyne Recrystallization in fibrous and particulate metal matrix composites Mater. Sci. Eng. A, 135 (1991), pp. 281-285

[36] U.R. Kattner Phase diagrams for lead-free solder alloys JOM, 54 (12) (2002), pp. 45-51

[37] J.W. Cahn The impurity-drag effect in grain boundary motion Acta Metall., 10 (1962), pp. $789-798$

[38] K. Lücke, H.P. Stüwe On the theory of impurity controlled grain boundary motion Acta Metall., 19 (10) (1971), pp. 1087-1099

[39] M. Hillert, B. Sundman A treatment of the solute drag on moving grain boundaries and phase interfaces in binary alloys Acta Metall., 24 (18) (1976), pp. 731-743

[40] R. Le Gall, J.J. Jonas Solute drag effects during the dynamic recrystallization of nickel Acta Mater., 47 (17) (1999), pp. 4365-4374

[41] D.G. Cram, X.Y. Fang, H.S. Zurob, Y.J.M. Bréchet, C.R. Hutchinson The effect of solute on discontinuous dynamic recrystallization Acta Mater., 60 (18) (2012), pp. 6390-6404

[42] M.A. Bhatia, I. Adlakha, G. Lu, K.N. Solanki Generalised stacking fault energies and slip in $\beta$-tin Scr. Mater., 123 (2016), pp. 21-25

[43] Y. Kinoshita, N. Ohno Energetics of slip deformation in beta-Sn: a first-principles study Key Eng. Mater., 626 (2014), pp. 46-49

[44] G. Ren, M.N. Collins The effects of antimony additions on microstructures, thermal and mechanical properties of Sn-8Zn-3Bi alloys Mater. Des., 119 (2017), pp. 133-140

[45] E.O. Hall The deformation and aging of mild steel Proceedings of the Physical Society Section B, 64 (1951), pp. 747-753

[46] N.J. Petch The cleavage strength of polycrystals The journal of Iron and Steel Institute, 174 (1953), pp. 25-28 